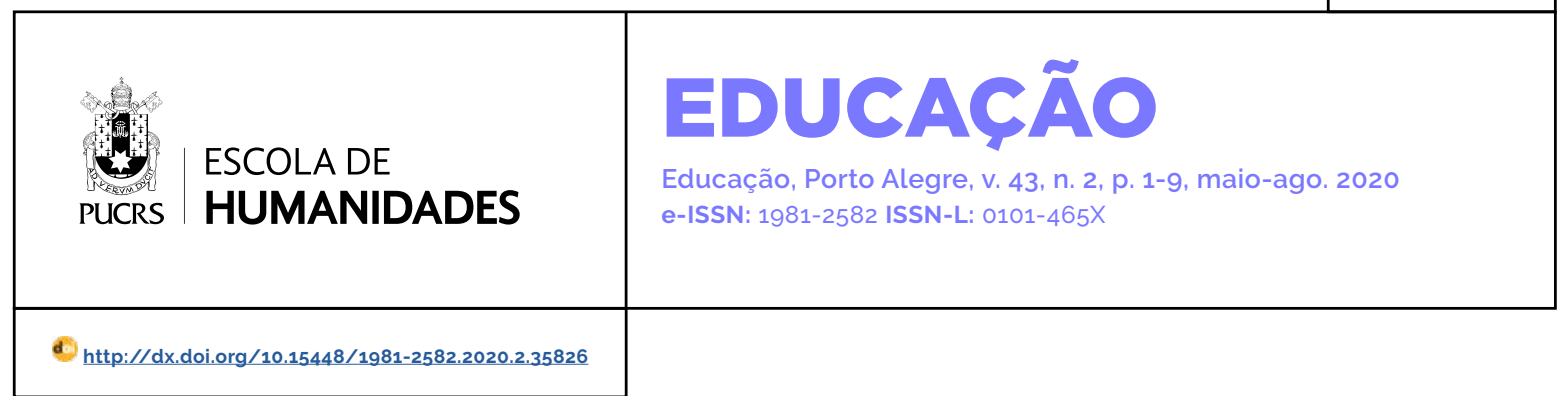

DOSSIÊ - FORMAÇÃO HUMANA EM MOVIMENTO

\title{
A literatura enquanto práxis educativa emancipatória e as possibilidades formativas dos Bildungsroman
}

\author{
Literature as emancipatory educational praxis and the formative possibilities \\ of the Bildungsroman \\ La literatura como praxis educativa emancipadora y las posibilidades formativas de \\ los Bildungsroman
}

Neiva Afonso Oliveira ${ }^{1}$

orcid.org/0000-0002-5513-5530

neivaafonsooliveira@gmail.com

\section{Fausto dos Santos \\ Amaral Filho'}

orcid.org/0000-0002-3800-0706

faustodossantos@outlook.com

Recebido em: 30 set. 2019. Aprovado em: 10 jun. 2020.

Publicado em: 2 dez. 2020.
Resumo: O texto discute o modo de compreensão dos Bildungsroman, da arte e da formação humana nos formatos da Bildung alemã. Levanta questões, em primeiro lugar, sobre os caminhos que a racionalidade moderna foi tomando, com prejuizo da arte e da filosofia como maneiras do conhecer se realizar. Em segundo lugar, e tendo presente o que foi dito relativamente às necessidades de produção de sentido para além do que é racional, detecta-se que a literatura pode exercer um papel fundamental para a formação humana. Ainda que pensemos que, em última instância, toda a literatura é formativa, debruçamo-nos sobre um caso emblemático: os romances de formação, dimensões literárias da formação do eu. Como caso exemplar de literatura que descreve, retrata a formação do sujeito, ainda na segunda parte do texto, trazemos uma abordagem sobre os Bildungsroman como oportunidade de resgate entre o que se perdeu na modernidade em termos de uma subjetividade que aflorara, apesar do progresso das ciências e do avanço da técnica. O texto traz como conclusão a necessária ênfase nos processos formativos que promovam os interesses integrais da multiplicidade das possibilidades humanas, entre eles, a emancipação dos sujeitos. Palavras-chave: práxis educativa, Bildung, Bildungsroman, emancipação

Abstract: The text discusses the way of comprehension about the Bildungsroman, Art and human formation along the lines of German Bildung. Firstly, it brings up questions about the ways that modern rationality has been chosen with losses to Art as well as to other ways of knowledge. Secondly, and having in mind what is often said relatively to necessities of meaning production beyond to what is rational, we get to catch that literature can play a very important role to human formation. Although, we think that, at last, all literature is formative, we lean over an emblematic case: romances of formation, literary dimensions of self's formation. As an exemplary literature case which describes portraying the subject's formation, in the second part of the text, we bring an approach about Bildungsroman as an opportunity of rescuing between what was lost in Modernity relatively to a subjectivity that outcropped, besides science progress and technical advance. As conclusion, it's said the necessary enphasis in formative processes which promote complete interests on human possibilities - of emancipation, among the mentioned possibilities. Keywords: educative praxis, Bildung, Bildungsroman, emancipation

Resumen: El texto discute el modo de comprensión de los Bildungsroman, de la arte y de la formación humana en los formatos de la Bildung alemana. Primeramente, señala cuestiones sobre los caminos que tomó la racionalidad moderna, a partir de prejuicios de la arte y de la filosofia como maneras del conocer y del realizarse. En segundo lugar, detecta, teniendo lo que fue dicho en relación a las necesidades de producción para allá de lo que es racional, que la literatura puede tener un papel fundamental para la formación humana. Aunque 
pensemos que toda la literatura es, en ultima instancia, formativa, levamos en cuenta un caso emblemático: los romances de formación, las dimensiones literárias de la formación del yo. Como ejemplo de una literatura que descrebe asi como retrata la formación del sujeto, traemos en la segunda parte del texto una abordaje cuanto a los Bildungsroman encuanto oportunidad de rescate entre lo que fue perdido en la modernidad en los termos de una subjetividad floreciente, a pesar de del progreso de la ciência y de los avances de la tecnica. El texto trae como conclusión una énfasis necesaria en los procesos formativos que promovieron los intereses integrales de la multiplicidad de posibilidades humana, entre esas la emancipación del sujeto.

Palabras clave: praxis educativa, Bildung, Bildungsroman, emancipación

Nunca antes na história da humanidade, viu-se a homogeneização da existência como em nossos dias. Isto que chamamos de globalização pode ser compreendido como a efetivação da referida homogenia operada, sobretudo, pelo modo de produção capitalista, que tem, em última instância, a tecnociência como o seu fundamento epistemológico. Afirmando-se globalmente como a única forma adequada de produção da existência humana, tal "racionalidade científica é também um modelo totalitário, na medida em que nega o caráter racional a todas as formas de conhecimento que não pautarem pelos seus principios epistemológicos e pelas suas regras metodológicas" (Santos, 2010, p. 21). Principios e regras que, ao fim e ao cabo, intentam produzir a mensuração de objetos. Quando então, "conhecer significa quantificar" (Santos, 2010, p. 27), ${ }^{2}$ e quantificar a maneira mais precisa de dominação do mundo.

Talvez por isto mesmo, "se esse desejo de dominação é inerente à ciência moderna" (Japiassu, 1983, p. 77), constituindo a sua possibilidade mais própria, é que podemos dizer que, se segue sendo certo que a dita racionalidade científica teve um papel libertador na aurora do seu surgimento, o mesmo não pode ser dito tendo em vista o seu desenvolvimento ulterior. Sendo mais apropriado dizer que "aquele mesmo empreendimento que em um momento deu ao homem as ideias e a força para se libertar dos medos e preconceitos de uma religião tirânica, agora faz dele um escravo dos seus interesses" (Feyerabend, 2011, p. 94), dominando praticamente todos nós.

Sendo assim, se esse é o modelo civilizacional que, produzido, pretende manter-se, disseminando-o, eliminando toda e qualquer possibilidade diversa "(...) à medida que nossas ciências e nossas artes avançaram no sentido da perfeição", (Rousseau, 1983, p. 337) certamente não é por um mero acaso que haja um modelo educacional que the corresponda ipsis litteris. Pelo que, "quase todas as disciplinas científicas são matéria obrigatória em nossas escolas" (Feyerabend, 2011, p. 92), em detrimento de tantos outros campos do saber, como a arte, por exemplo, que, mesmo quando presente em sala de aula, já cedeu o seu "lugar a formas de consciências mais elevadas" (Hegel, 1952, p. 220), pois "a sua forma já deixou de satisfazer as exigências mais altas do espirito" (Hegel, 1952, p. 221), permanecendo ali "Como um cão tolerado pela gerência/ Por ser inofensivo" (Pessoa, 1999. p. 66), como mormente costuma-se pensar.

Para nós, é assim, achando que a Ciência é a única capaz de nos situar em meio à realidade, justamente porque pressupomos que ela é a "forma superior do conhecimento" (Pinto, 1969. p. 63), que a tarefa da Educação passa a coincidir com a tarefa da Ciência. Já que a Educação deve preparar o cidadão para o mundo tal qual ele é.

Diante do status vigente, onde "o Estado e a Ciência trabalham rigorosamente juntos" (Feyerabend, 2011, p. 92), representando, sobretudo, os interesses do capital, que, no mais das vezes não coincidem com os interesses mais amplos das possibilidades humanas face ao mundo, ${ }^{3}$ levamos obrigatoriamente nossos filhos para a escola para que aprendam a aderir vigorosamente ao mundo que vigora, adentrando, o mais prontamente possivel, no mercado de trabalho. A educação, pensada assim, é o modo através

\footnotetext{
"O rigor científico afere-se pelo rigor das medições. As qualidades intrínsecas do objeto são, por assim dizer, desqualificadas e em seu lugar passam a imperar as quantidades em que eventualmente se podem traduzir. O que não é quantificável é cientificamente irrelevante" (Santos, 2010, p. 27-28)

3 Ao que tudo indica já se foi o tempo em que podiamos dizer com Kant que "todos os progressos na civilização, pelos quais o homem se educa, têm como fim que os conhecimentos e habilidades adquiridos sirvam para o uso do mundo, mas no mundo o objeto mais importante ao qual o homem pode aplicá-los é o ser-humano, porque ele é seu próprio fim último" (Kant, 2006, p. 21).
} 
do qual tornamos a mercadoria que somos mais atrativa para o pronto consumo, para que nós mesmos também possamos consumir. Afinal, "vivemos em tempos nos quais o capital tornou-se o nosso mestre, conduz nossos atos e nos induz ao consumo fugidio de objetos produzidos pelo capitalismo científico-tecnológico" (Pereira, 2013, p. 492). Quando fica, então, auferida a nossa inclusão.

Já faz parte do imaginário geral que o professor é aquele por meio do qual se produzem todas as outras profissões, apenas. É claro que o trabalho é, sem sombra de dúvidas, uma das dimensões mais importantes da nossa existência. Contudo, não é a única. O ser humano não é apenas e tão somente um trabalhador. Também é aquele que, no mínimo, conhece e ama (Reich, 2001). Ainda que, reprimido em suas potencialidades, possa ser apequenado.

Estando a educação comprometida com a reprodução do mesmo, é preciso que ela própria se torne outra para que um outro mundo se torne possivel. Porém, sendo ela própria um ser-no-mundo que conflui decisivamente para a produção do mesmo, parece que dificilmente o mundo possa ser outro. Entretanto, sabemos que a mudança do mundo não se faz de uma hora para outra, sendo preciso, antes, criar as condições para que o novo aconteça.

Para que possamos vislumbrar, semeando, as alternativas de um mundo diverso, onde a própria possibilidade da diversidade da produção de sentidos possa se efetivar, pensamos que a arte pode desempenhar um papel decisivo. Afinal, diferentemente da linguagem científica, estruturada a partir da monossemia das palavras - não é meramente por acaso que por meio de tal monossemia tenhamos construido um mundo cada vez mais homogêneo -, a linguagem artística, acolhendo por princípio a intrinseca polissemia das palavras, é capaz de, aceitando a possibilidade do diverso, produzir um mundo plural, ${ }^{4}$ mais condizente com as potencialidades da humanidade inerentes ao nosso existir. Sendo, portanto, a linguagem artística mais habilitada para compreender aquilo "que o cálculo ignora, ou seja, a vida, os sentimentos, a alma, nossos problemas humanos" (Morin, 2011, p. 25).

Dessa maneira, uma educação que não veja a arte apenas e tão somente como um momento meramente recreativo, por meio do qual os educandos possam relaxar ludicamente as tensões oriundas da seriedade das disciplinas científicas, mas sim como uma forma válida de produção e de compreensão do mundo, na medida em que é uma forma privilegiada de compreensão do fenômeno humano naquilo que mais propriamente o constitui, pode ser o primeiro passo para que possamos vislumbrar a possibilidade de emergência do efetivamente novo, ao invés do aprofundamento cada vez maior em direção ao mesmo, que é praticamente a única coisa que a tecnociência é capaz de fazer. ${ }^{5}$

Tendo tudo isso em vista, no momento, nos interessamos sobremaneira pela literatura. Pois é a literatura que mais propriamente visa a ser não como um dado, mas sim como um poder-ser. "Pela ficção, pela poesia, abrem-se novas possibilidades de ser-no-mundo na realidade cotidiana" (Ricoeur, 1977. p. 57). É a literatura que privilegiadamente franqueia a possibilidade de nos compreendermos como um outro, descerrando, assim, a dimensão do sentido para o acolhimento da alteridade. Em meio à produção literária, "o autor escreve para se dirigir à liberdade dos leitores, e a solicita para fazer existir a sua obra" (Sartre, 2004, p. 43). Na leitura literária, "quanto mais experimentamos a nossa liberdade, mais reconhecemos a do outro" (Sartre, 2004, p. 43). Mas, de que maneira a liberdade, ou seja, o ônus de produzirmos a existência propriamente humana para além das nossas determinações fisiológicas adentra na literatura?

Para Paul Ricoeur, isso se dá pelas características inerentes à própria escritura de uma obra

\footnotetext{
4 Para um aprofundamento das relações entre a monossemia da linguagem científica e a polissemia da linguagem poética, ver: Amaral Filho, 2018.

5 "Evidentemente que a Ciência avança, quem seria capaz de negá-lo? Mas para onde avança a Ciência? A Ciência só pode avançar em direção ao mesmo, não permitindo que nada de novo aconteça para fora do seu próprio âmbito que, evidentemente, é sempre o mesmo: a repressão da linguagem em prol do delineamento do mundo. Portanto, se a Ciência só pode avançar em direção ao mesmo, o que avança na Ciência é justamente o delineamento do mundo a partir da repressão da linguagem. Sendo assim, a Ciência é aquela que, avançando, impõe cada vez mais limites ao mundo, transformando-o em uma coisa só" (Amaral Filho, 2018, p. 388, grifo do autor).
} 
que o autor inexoravelmente deixa para os seus leitores: "em outras palavras, graças à escrita, o 'mundo' do texto pode fazer explodir o mundo do autor" (Ricoeur, 1977, p. 53, grifo do autor), tornando o texto livre em relação àquele que o produz, tanto do ponto vista das condições psicológicas, quanto do ponto de vista das condições sociológicas da sua produção. Dirigindo-se, pois, à liberdade do leitor. Provavelmente seja dai que surge a possibilidade de Sartre nos dizer que "a literatura é um exercício de generosidade" (Sartre, 2004, p. 42). ${ }^{6}$

Pois como aquele que escreve reconhece, pelo próprio fato de se dar ao trabalho de escrever, a liberdade de seus leitores, e como aquele que lê, pelo simples fato de abrir o livro, reconhece a liberdade do escritor, a obra de arte, vista de qualquer ângulo, é um ato de confiança na liberdade dos homens. (Sartre, 2004, p. 51)

Liberdade essa que, inexoravelmente, nos lança às necessidades da produção de sentido,"significantes em busca de significado" (Stein, 2001, p. 70) que somos. Assim, se levamos a sério o fato de o autor deixar para nós leitores a sua obra, "o que o texto significa não coincide mais com aquilo que o autor quis dizer" (Ricoeur, 1997, p. 53). Ainda que, evidentemente, o autor, ao escrever, tenha lá as suas intenções, é ao leitor destinada a tarefa de ressignificar a obra a partir do seu próprio mundo. Sendo assim, "o texto deve poder, tanto do ponto de vista sociológico quanto psicológico, descontextualizar-se de maneira a deixar-se recontextualizar numa nova situação: é o que justamente faz o ato de ler" (Ricoeur, 1997, p. 53). Transcendendo as condições mundanas da sua produção, o texto se abre "a uma sequência ilimitada de leituras, elas mesmas situadas em contextos sócio-culturais diferentes" (Ricoeur, 1997, p. 53). Endereçado, portanto, a todos os seus possiveis leitores cuja tarefa será não propriamente a compreensão daquilo que o autor quis dizer, mas antes, a compreensão das possibilidades de si-mesmo a partir daquilo que foi deixado pelo autor e que precisa ser, portanto, apropriado pelo leitor.?

Tal estar lançado do texto ao reino das possibilidades é efetivado sobretudo pelas obras literárias. Onde o que efetivamente importa não é a descrição mensúravel dos objetos dispostos no mundo como realidades dadas, e que, portanto, podem ser referenciados univocamente pela linguagem que lhes convém. A ficção literária refere-se ao mundo "não mais somente no plano dos objetos manipuláveis, mas no plano que Husserl designava pela expressão de Lebenswelt, e Heidegger pela de ser-no-mundo" (Ricoeur, 1997, p. 56). Ou seja, a linguagem literária atinge aquilo que mais propriamente nos convém, abrindo brechas para que possamos compreender e agir diante das necessidades da produção da existência humana. Talvez por isso mesmo possamos afirmar, inclusive, que as ciências voltadas para a compreensibilidade das questões especificamente humanas, "as chamadas ciências do espírito, estão mais próximas da poesia" (Frege, 2002, p. 18). ${ }^{8}$

Assim, indo com Frege, mas para além de Frege, quando nos diz que "na poesia, naturalmente, as palavras têm apenas sentido" (Frege, 1978, p. 195), sendo totalmente privadas do horizonte referencial, afastadas, portanto, de toda e qualquer designação da realidade, Paul Ricoeur afirma que "não há discurso de tal forma fictício que não vá ao encontro da realidade" (Ricoeur, 1997, p. 56). Para o nosso hermeneuta, a dita realidade é "a categoria última a partir da qual toda a linguagem pode ser pensada como o ser dito da realidade" (Ricoeur, 1983, p. 461). Afinal, "é necessário que alguma coisa seja, para que alguma coisa seja dita" (Ricoeur, 1983, p. 461). Portanto, é justamente pela abolição daquilo que Ricoeur chama de referência de primeiro nivel, que opera, sobretudo, a designação de objetos, que a linguagem ficcional literária é capaz de referir-se privilegiadamente ao

6 "Pois chamo de generosidade uma afeição que tem a liberdade por origem e por fim" (Sartre, 2004, p. 42).

7 "Em primeiro lugar, a apropriação está dialeticamente ligada ao distanciamento típico da escrita. Esta não é abolida pela apropriação. Pelo contrário, é sua contrapartida. Graças ao distanciamento pela escrita, a apropriação não possui mais nenhum dos caracteres da afinidade afetiva em relação ao autor. A apropriação é exatamente o contrário da contemporaneidade e da congenialidade, é compreensão pela distância, compreensão a distância" (Riçeur, 1997, p. 58).

8 Pelo que, para Frege, "são menos científicas do que as ciências exatas" (2002, p. 18). 
mundo propriamente humano, que não se reduz aos fatos meramente objetificáveis. Eis o que diz Ricoeur: "Minha tese consiste em dizer que a abolição de uma referência de primeiro nivel, operada pela ficção e pela poesia, é a condição de possibilidade para que seja liberada uma referência de segundo nivel" (Ricoeur, 1997, p. 56). Dito de outra forma, o discurso poético "é aquele no qual a epokê da referência ordinária é a condição negativa da manifestação de uma referência de segundo nivel" (Ricoeur, 1983, p. 462). Referência essa que, como dissemos, é capaz de desvelar o horizonte da existência humana, ampliando as possibilidades de compreensibilidade do mundo. Mundo esse que é sempre o nosso, constituído por tudo aquilo que a linguagem alcança. O que leva Ricoeur a afirmar que "a ficção é o caminho privilegiado da realidade" (Ricoeur, 1997, p. 57). Sendo a obra literária, portanto, "a mediação pela qual nos compreendemos a nós mesmos" (Ricoeur, 1997, p. 57). É a partir da alteridade que a obra apresenta que se pode constituir um si-mesmo. Um si-mesmo que, constituido pela alteridade da obra, pode reconhecer, sobretudo, a possibilidade do outro, visto que essa é a sua própria possibilidade. Rompendo, assim, com uma visão homogênea do mundo. Ao fim e ao cabo, "só nos compreendemos pelo grande atalho dos sinais de humanidade depositados nas obras de cultura" (Ricoeur, 1997, p. 58). Sendo a literatura um dos seus maiores expoentes.

É tendo o que foi dito presente que julgamos que a literatura pode exercer um papel fundamental para a formação humana. Contudo, ainda que pensemos que, em última instância, toda a literatura é formativa, no momento queremos nos debruçar sobre um caso emblemático, que, certamente, mostrará aquilo que estamos pensando, os romances de formação, dimensões literárias da formação do eu.

\section{Bildungsroman: um caso exemplar}

Traduzindo o espírito da Bildung, o romance de formação é o tipo de livro mais profundo do que normalmente aparenta ser. Focado em um protagonista (jovem ou criança), narra a mudança dos personagens durante sua formação e na passagem da infância à vida adulta.

A definição inaugural do Bildungsroman por Morgenstern entende sob o termo aquela forma de romance que "representa a formação do protagonista em seu início e trajetória até alcançar um determinado grau de perfectibilidade". Uma tal representação deverá promover também "a formação do leitor, de uma maneira mais ampla do que qualquer outro tipo de romance". (Maas, 2000, p. 19)

O romance de formação tem como objetivo acompanhar a trajetória de um sujeito, desde sua infância ou juventude até seu amadurecimento na idade adulta. Em outras palavras, no percurso descritivo da sua história, é narrada a vida do protagonista em formação, o desenvolvimento individual e na sociedade, sua vida amorosa, seus sucessos e fracassos. O personagem vai seguindo seu caminho e, na sequência da descrição do processo, temos a exposição de como desenvolve seu intelecto, seu senso crítico, sua apreensão política da realidade, o modo como adquire cultura, incluindo sua visão do mundo e de seu contexto em geral.

Como a Bildung pressupõe uma formação humana universal, o romance de formação é narrativa do desenvolvimento de todas as potencialidades do ser, é relato da deliberação a respeito do autocultivo do protagonista e de sua decisão de experimentar a vida de acordo com uma prescrição ética do viver. Assim, a narrativa de um romance de formação comporta todos os aspectos da vida do protagonista, inclusive seus sentimentos, seus gostos, suas habilidades, a forma como lida com todas essas aquisições e, fundamentalmente, o modo como está realizando sua autoformação.

A trama e a força dramática do enredo nos romances de formação fazem com que o protagonista descreva sua rede de relações como parte importante de sua autoformação. Os romances de formação são artefatos dos modos de ser e de expressar as vivências e de resistir aos instantes de desumanização. Conforme Freitag (2001) 'o romance contém 'provas', às quais o herói é submetido - o amor, o sacrificio do amor, a renúncia -, que aprimoram sua personalidade 
e a enobrecem moralmente, o que se reflete em sua inserção transformadora do mundo" (p. 69). Em outras palavras, ao trazer de forma esmiuçada o processo de desenvolvimento do ser humano em sua totalidade, o Bildungsroman expõe com muita propriedade características que o individuo necessita aprimorar ao longo de sua trajetória.

A sensibilidade é o que aflora ao pesquisarmos um gênero literário ${ }^{9}$ que tem o foco em obras de autores como Rousseau, Goethe, Pestalozzi, Thomas Mann, Hoffmann, Dostoiévski e outros, pois suas obras têm em comum justamente o sentimento, a sensação, o sentir, o eu e o formar-se e se utilizam de "técnicas narrativas experimentais como o fluxo da consciência" (Santos \& Maas, 2018, p. 104). Rousseau, a exemplo da maioria dos autores alemães - Goethe é um bom exemplo disso com seu Wilhelm Meister - invocava a inviolabilidade dos ideais pessoais sensiveis contra os poderes do Estado e as pressões da sociedade. Em conexão com a sensibilidade, pode-se incluir também a ética e a estética, pois têm a ver com a parte sensivel do ser humano e, também, com a formação humana. Segundo Hermann (2008):

A estetização da ética situa-se nesse anseio de preencher o vazio deixado pela queda das justificações metafisicas, justamente porque a estética sempre se interpôs contra o rígido racionalismo, para destacar que as forças da imaginação, da sensibilidade e das emoções teriam maior efetividade para o agir do que a formulação de princípios abstratos e do que qualquer fundamentação teórica da moral. (p. 17)

A respeito da viagem como processo formativo inserido e levado em conta na Bildung - pois quando o sujeito viaja, é exposto às mais diversas experiências, depara-se com diferentes culturas e idiomas e essa prática dimensiona sua formação, não deixando de ser um ato de autoformação -, essa se conecta com o sentido de alteridade, tão essencial para a Bildung. Viajar possui o caráter prático e dinâmico e nada mais transformador do que o deslocamento, o sair de si, pois além de ser um processo que educa e forma o sujeito em processo de aprendizagem, torna-o outro, através das experiências e das práticas que vivencia e às quais vai se submetendo.

De acordo com Berman ${ }^{10}$ (1983 citado por Suarez, 2005, p. 195), Schlegel ${ }^{11}$ traduz exemplarmente o exercício da viagem como expressão de alteridade quando afirma: "é por isso que, certo de reencontrar-se, o homem sai de si mesmo para se buscare encontrar o complemento de seu ser no mais íntimo da profundidade do outro. O jogo da comunicação e da aproximação é sentido e força de vida".

Ainda, lembrando Berman, trazemos o entrelaçamento entre Bildung e a expressão do conceito trabalho, pois o ideal da Bildung é o cultivo da totalidade da humanidade do homem e esse cultivo acontece pela via do conhecimento de diferentes culturas, do cultivo de si e do aprimoramento das qualidades humanas. Do lenitivo de suas falhas, surge o trabalho com função também educadora nesse rol de desdobramentos da Bildung alemã. Rousseau anseia que seu discipulo Emilio trabalhe, o jovem Meister não trabalhará como comerciante conforme seu pai desejara, porém atuará, dirigirá uma trupe de teatro mambembe e assim há, no decorrer da descrição da vida dos protagonistas, episódios ligados à atividade laboral como instâncias ou dimensões da sua formação.

Conforme Flickinger (2009, p. 179), "é a integração do individuo no mercado de trabalho que lhe providencia não apenas meios materiais para sua subsistência, senão, antes de tudo, o reconhecimento como membro valioso da comunidade". Emilio, o já citado discipulo de Rousseau, também trabalhará, será marceneiro ${ }^{12}$ (menuiserie), pois, por meio do trabalho, aprendem-se habilidades técnicas e intelectuais, bem como a convivência

\footnotetext{
9 É grande o impacto na Alemanha dos anos 1795 e 1796 quando foi escrito Os anos de aprendizado de Wilhelm Meister (Goethe) e inaugura o gênero literário dos Bildungsroman. Atrás desse, outros se sucedem, em tempos longínquos, por volta de 1876, como 0 Adolescente, de Dostoiévski, por exemplo.

10 Antoine Berman, filósofo, crítico literário e teórico francês da tradução do século XX.

11 Friedrich Schlegel foi um poeta, crítico literário, filósofo, filólogo e tradutor alemão. Viveu na mesma época de Goethe, século XVIII.

12 Carpinteiro seria tradução errada do que Rousseau preconiza como profissão para seu discipulo. Menuiserie exige inteligência, criatividade, discernimento estético por parte do artífice. A esse respeito, ver o artigo do professor Oscar José de Almeida (2002), intitulado A educação musical de Emílio.
} 
com o diferente e a compreensão de valores, já que o trabalho ensina ao homem o senso de responsabilidade, o treino de habilidades novas e o manejo de ter um tempo de executá-las. O trabalho influencia o caráter, a disciplina, a busca de metas e objetivos, além de responsabilidades. Citando Berman (1983 citado por Suarez, 2005, p. 195):

Já na obra de Goethe, Os anos de viagem de Wilhelm Meister, sequência de Os anos de aprendizado, o protagonista inscreve-se no circulo concreto dos deveres e tarefas se esforça nos limites de uma atividade determinada - é levado a descobrir-se em meio aos diversos encargos e provas da vida material e social.

Levando em conta que o conceito de Bildung pressupõe o cultivo dos mais variados potenciais, dons e talentos do ser humano, também pode ser considerado enquanto modelo de formação como interligado à filologia, ou seja, o estudo da língua em textos escritos, incluindo as escritas antigas, a cultura de povos diversos, e o estudo e a interpretação de textos literários.

Enquanto modelo de formação, o horizonte da Bildung é a educação universal do ser humano, aquela que une razão e emoção, aptidões e sentimentos, intelecto e coração, saberes acadêmicos e saber sentir. Desse modo, desenvolver todas as potencialidades do ser humano, estar imbuído de humanidade, restar encharcado de emoções, de amor de si, de ética, de moral, de estética, e compreender que o homem não pode se formar sem esses princípios básicos da vida, são palavras de ordem da Bildung. Para formar-se, o homem reflete, desenvolve-se e se transforma em algo melhor e mais completo do que já é. A legitimação da formação humana transcende os saberes intelectuais e os saberes docentes e teóricos, pois a formação universal é também espiritual, abrange a visão de mundo, a vivência e a arte de viver e se reconstruir no mundo e com o mundo. Segundo Hermann (2008, p. 18):

(...) aqui podemos lembrar a inscrição no templo de Delfos "conhece-te a ti mesmo" (gnôthiseauton), exortando a fazer do eu um tema reflexivo -, passando pelo movimento romântico e chegando à atualidade como uma for- ma de configurar e conduzir a vida de modo correto, por meio da invenção das práticas cotidianas. Entendo que esse modo de conceber a ética apresenta convergência com a ideia de Bildung na tradição do idealismo alemão (...).

A partir de Hermann, ressalta-se a possibilidade de estudo relacionada ao incentivo do autoconhecimento e da autorreflexão, pois Bildung também abrange o cultivo e o cuidado de si, que nada mais são do que metodologias que propiciam que nos conheçamos, tomemos pé do mundo e procuremos potencializar todas nossas lateralidades ou dimensões. A estética diz respeito a sentimentos e por meio da sensibilidade, é possivel atingir um conhecimento maduro - o sentir faz progredir o intelecto e humaniza o indivíduo.

Considerando as experiências e as aprendizagens adquiridas pelos homens por meio da sensibilidade ao se lançar em viagens, bem como o fazer parte do mundo do trabalho, conclui-se que o ser humano, ao aperfeiçoar-se, torna-se capaz e competente para modificar não somente a si mesmo, mas também transformar e recriar a sociedade. "O viajante é uma perpétua testemunha", afirma Jean-Paul Sartre (2015, p. 105).

Uma das principais características ou faculdades do humano, a perfectibilidade, ou o contínuo aperfeiçoar-se juntamente com uma abertura ao indeterminado que se diferencia da completa determinação instintiva dos animais é a alavanca para o autoconhecimento. Assim, tem-se que:

O que é característico do ser humano
é que, ao contrário do que sucede com
os outros animais, os conteúdos e ha-
bilidades especíicos que preenchem
suas capacidades originais dependem
quase inteiramente do meio em que ele
se desenvolve, isto é, do seu contato
com as coisas que o cercam e com os
seus semelhantes. (Almeida, 2002, p. 7)

A noção de perfectibilidade carrega consigo toda uma carga de significados ofertados a ela pela tradição filosófica e está a tal ponto enraizada nos modos de compreender nossa existência que é capaz de orientar-nos em como e o quanto o homem pode guiar a si mesmo no pensar e no agir e, por consequência, exercitar-se no uso de sua 
liberdade e de suas capacidades. Tal perspectiva aparece na maior parte dos romances de formação e em obras como Emílio de Rousseau e Os anos de aprendizado de Goethe essa veiculação ou relato da formação do protagonista torna-se mais emblemática. No caso de Emílio, quando Rousseau deixa claro o que se deve e o que se pode fazer (o que é uma constante nas narrativas autoformativas, e também em boa dose nos Bildungsroman), nos é revelado todo o cuidado que se deve ter em relação à formação ao nivel de parecer atribuir à educação elementos salvíficos ou redentores do humano, mas, mais do que isso, delega, em iguais partes de responsabilidade, à razão e ao sentimento, a obrigação de nutrir o homem e de conduzi-lo à sua formação.

\section{Considerações finais}

Ainda que saibamos que o mundo ocidental foi produzido a partir da repressão da compreensão artística do mundo, relegando-a para um plano cognitivamente menor, fundamentalmente em relação à técnica e à ciência, tentou-se mostrar aqui, justamente por isso, que diferentemente do que hegemonicamente está posto, antes de ser, apenas e tão somente, coisa do passado, no momento presente do mundo, a arte pode ser uma possibilidade privilegiada para produzirmos o nosso futuro. Afinal, diante da preponderante homogeneização que a existência contemporânea nos impõe, a arte - pelo próprio princípio linguístico que a constitui, a polissemia - pode nos mostrar semanticamente os múltiplos caminhos que ainda podemos seguir.

Dentre todos os modos de ser da arte, destacamos a literatura de ficção. Assim destacada, apoiando-nos principalmente na hermenêutica de Paul Ricoeur, argumentamos em favor da potencialidade literária ficcional de atingir as especificidades mais próprias do existir humano, desvelando, dessa maneira, a sua pertinência em relação à compreensão e à produção do mundo. Dito mais diretamente, sustentamos a adequação da literatura de ficção aos processos formativos que estejam à altura e sejam proporcionais aos interesses integrais da multiplicidade das possibilidades humanas.
Com o intuito de exemplificar a referida potencialidade, recorremos aos romances de formação. Esse gênero da literatura de ficção mostra-se essencialmente engajado com as questões inerentes a tudo aquilo que, ao fim e ao cabo, o conceito de Bildung procura abarcar - a formação e a autoformação do eu, desde sempre inserido no meio social.

\section{Referências}

Almeida, O. J. (2002). A educação musical de Emílio. Rapsódia, Almanaque de Filosofia e Arte, (2), 7-35

Amaral F., F. S. (2018). Ética e Estética são Um? O que isto pode ter a ver com a Educação escolar? Revista Educação \& Realidade, 43, 387-399. https://doi. org/10.1590/2175-623660334

Feyerabend, P. (2011). A Ciência em uma Sociedade Livre. São Paulo: Editora Unesp.

Flickinger, H-G. (2009). A dinâmica do conceito de formação (Bildung) na atualidade. In Â. V. Cenci, C. A. Dalbosco, \& E. Mühl. Sobre filosofia e educação: racionalidade, diversidade e formação pedagógica. Passo Fundo: UPF.

Frege, G. (1978). Digressões sobre o Sentido e a Referência. In Lógica e Filosofia da Linguagem. São Paulo: Editora Cultrix.

Frege, G. (2002). O Pensamento: uma investigação lógica. In Investigações Lógicas. Porto Alegre: Edipucrs.

Freitag, B. (2001). O individuo em formação: diálogos interdisciplinares sobre educação. ( $3^{\mathrm{a}}$ ed). São Paulo: Cortez.

Hegel, G. W. F. (1952). Estética: a Ideia e o Ideal. Lisboa: Guimarães \& $C^{a}$ Editores.

Hermann, N. (2008). Ética e estética. Porto Alegre: EDIPUCRS.

Japiassu, H. (1983). A pedagogia da incerteza e outros estudos. Rio de Janeiro: Imago Editora.

Kant, I. (2006). Antropologia de um ponto de vista pragmático. São Paulo: Iluminuras.

Maas, W. P. M. D. (2000). O cânone mínimo: o Bildungsroman na história da literatura. São Paulo: Editora Unesp.

Morin, E. (2011). Rumo ao Abismo? Ensaio sobre o destino da humanidade. Rio de Janeiro: Bertrand Brasil.

Pereira, M. R. (2013). Os profissionais do impossivel. Educação \& Realidade, 38(2), 485-499. https://doi. org/10.1590/S2175-62362013000200008

Pessoa, F. A. N. (1999). Tabacaria. In Poesias. Porto Alegre: L\&PM.

Pinto, Á. V. (1969). Ciência e Existência. Rio de Janeiro: Paz e Terra.

Reich, W. (2001). Psicologia de Massas do Fascismo. São Paulo: Martins Fontes. 
Ricoeur. P. (1983). A Metáfora Viva. Porto: Rés-Editora.

Ricoeur. P. (1977). Interpretação e Ideologias. Rio de Janeiro: Livraria Francisco Alves Editora.

Rousseau, J-J. (1983). Discurso sobre as ciências e as artes. In Pensadores. São Paulo: Abril Cultural.

Santos, B. S. (2010). Um discurso sobre as ciências. São Paulo: Editora Cortez.

Sartre, J-P. (2004). Que é Literatura? São Paulo: Editora Ática.

Stein, E. (2001). Epistemologia e Critica da Modernidade. Ijui: UNIJUI.

\section{Neiva Afonso Oliveira}

Doutora em Filosofia pela Pontifícia Universidade Católica do Rio Grande do Sul (PUC-RS), em Porto Alegre, RS, Brasil; professora da Universidade Federal de Pelotas (UFPel), em Pelotas, RS, Brasil.

\section{Fausto dos Santos Amaral Filho}

Doutor em Filosofia pela Universidade Federal do Rio de Janeiro (UFRJ), no Rio de Janeiro, RJ, Brasil; professor da Universidade Tuiuti do Paraná (UTP), em Curitiba, PR, Brasil.

\section{Endereços para correspondência}

Neiva Afonso Oliveira

Universidade Federal de Pelotas - Faculdade de Educação

Rua Cel. Alberto Rosa, 154

Várzea do Porto, 96010-770

Pelotas, RS, Brasil

Fausto dos Santos Amaral Filho

Universidade Tuiuti do Parana

Rua Sydnei Antonio Rangel Santos, 238

Santo Inacio, 82010-330

Curitiba, PR, Brasil 